\title{
Thermal behaviour of strontium tartrate single crystals grown in gel
}

\author{
M H RAHIMKUTTY ${ }^{\dagger}$, K RAJENDRA BABU, K SREEDHARAN PILLAI, \\ $M$ R SUDARSANA KUMAR ${ }^{\ddagger}$ and C M K NAIR*
}

Department of Physics, ${ }^{*}$ Department of Chemistry, M.G. College, Thiruvananthapuram 695 004, India

†Department of Physics, M.S.M. College, Kayamkulam 690 502, India

MS received 18 May 1999; revised 13 November 2000

\begin{abstract}
Thermal behaviour of strontium tartrate crystals grown with the aid of sodium metasilicate gel is investigated using thermogravimetry (TG) and differential thermal analysis (DTA). Effect of magnetic field and dopant $(\mathbf{P b})^{2+}$ on the crystal stability is also studied using thermal analysis. This study reveals that water molecules are locked up in the lattice with different strengths in the grown crystals.
\end{abstract}

Keywords. Strontium tartrate; dopant; effect of magnetic field; thermal behaviour.

\section{Introduction}

Strontium tartrate tetrahydrate (SrT) crystallizes in orthorhombic system in the space group $P_{2_{1} 2_{1} 2_{1}}$ containing four molecules per unit cell with unit cell dimensions $a=$ $0.948, b=1.096$ and $c=0.946 \mathrm{~nm}$ (Bohandy and Murphy 1968). Most of the tartrate compounds are insoluble in water and decompose before melting. Hence, single crystals of such type of compounds cannot be grown by either slow evaporation or melt techniques. In this situation gel method is the appropriate one for their growth. The growth of single crystals of calcium tartrate was reported (Henisch et al 1965). Thermal behaviour of gel grown tartrates of yttrium and samarium was also reported recently (Jain et al 1997). In this paper we report the growth of strontium tartrate without any field, in the presence of magnetic field and in the presence of lead as dopant with the aid of sodium metasilicate gel.

\section{Experimental}

The chemicals used in this study were of BDH, AR grade. A test-tube diffusion method (Henisch 1973) was employed to grow strontium tartrate single crystals in a gel medium.

The growth experiments were carried out in test tubes using sodium metasilicate solution of density 1.03 and $1.035 \mathrm{~g} / \mathrm{cc}$. 1-2 $\mathrm{M}$ of tartaric acid solution was added to these solutions to form gels of $\mathrm{pH}$ values 5-10. Over the set gel an aqueous solution of strontium nitrate of varying strength $(0 \cdot 5-2 \mathrm{M})$ was gently poured.

\footnotetext{
*Author for correspondence
}

The chemical reaction taking place in the gel medium was as follows

$$
\mathrm{C}_{4} \mathrm{H}_{6} \mathrm{O}_{6}+\mathrm{Sr}\left(\mathrm{NO}_{3}\right)_{2} \rightarrow \mathrm{SrC}_{4} \mathrm{H}_{4} \mathrm{O}_{6}+2 \mathrm{HNO}_{3}
$$

The crystallization apparatus used in the present study were test tubes of $20 \times 200 \mathrm{~mm}, 15 \times 150 \mathrm{~mm}$ and $\mathrm{U}$ tubes of $17 \times 170 \mathrm{~mm}$. The test tube was filled with gel of density $1.035 \mathrm{~g} / \mathrm{cc}$ to a level of $100 \mathrm{~mm}$. The $\mathrm{pH}$ of the gel was adjusted to 5 using $1 \mathrm{M}$ of tartaric acid solution. The gel was kept undisturbed for a day. After setting the gel, the top solution of strontium nitrate $(1 \mathrm{M})$ was gently poured over the gel surface. Strontium nitrate diffused through gel and a white thin film appeared just below the gel surface. Tiny crystallites were visible within a day. The size and number of isolated crystals increased in about a week. Orthorhombohedral crystals were obtained in all the experiments, their number depending on various factors like molarity, density, $\mathrm{pH}$ values and quantity of solution. The maximum size of the crystals grown was about $6.51 \times 4.80 \times 3.60 \mathrm{~mm}^{3}$ (as shown in figure 1 ). As the crystals do not allow light nor reflect the same, the material need not be studied under transmitted or reflected petrological microscope. Hence the crystallinity is observed under a stereo binocular microscope (Carl Zeiss) and confirmed as single crystal.

In order to study the effect of dopants on the morphology and growth of strontium tartrate (SrT), $10 \%$ (W/V) solution of lead nitrate was also mixed with the top solution. Within two hours a white precipitate was observed at the gel solution interface of the lead doped samples at $\mathrm{pH}$ 8. After two days the length of the precipitate increased to a depth of $1.8 \mathrm{~cm}$ due to the diffusion of the top solution. After about a week the length of the precipitate increased to $4.3 \mathrm{~cm}$ and remained constant. There were few crystals 
in the lower part of the precipitate. The precipitate was transformed into dendrites which eventually yielded small crystals of lead doped strontium tartrate tetrahydrate (abbreviated as SrPbT). The diffraction patterns of grown crystals were analysed and the calculated ' $d$ ' spacing, $h k l$ and peak intensities were compared with those of strontium tartrate (for orthorhombic) reported in JCPDS files. The variation in the $d$ values for the doped sample ( $\mathrm{SrPbT})$ can be attributed to the accommodation of the impurity ions in the crystal. Relative intensities of the reflections from the same $h k l$ planes are found to vary in doped and undoped crystals. This is indicative of a change in conformation of the molecule due to doping, however small it be. The exact extent of change in conformation can be assessed only through single crystal XRD study which was not attempted in this work. Moreover to know whether $\mathrm{Pb}^{2+}$ occupy $\mathrm{Sr}$ sites or not, single crystal XRD study is necessary. Single crystals of strontium tartrate tetrahydrate were also grown by applying a magnetic field of $3 \times 10^{-2}$ Tesla (abbreviated as SrTMF). The magnetic field is applied between the sides of the test tube. The magnetic field is formed by two magnets kept at a distance varying from $1.5-2.5 \mathrm{~cm}$ with $0.05-0.03$ Tesla. The test tube is placed between the opposite poles of magnet.

When we apply a field perpendicular to the tube, path lengths of the diffusing ions increase which slow down the vertical displacement of the ions due to the increased resistance of the extra path which the ions have to travel. In effect this is equivalent to reducing the diffusion coefficient of the medium. The observed delay in the time of formation of the crystal in magnetic field is attributed to the decrease in the diffusivity of reaction ions. A later study of Higavshitani et al (1993) showed decreasing nucleation rate and increasing growth rate at values of $(B)$ magnetic field above 3 Tesla. The uniformity of grown layers improves with increasing magnitude of the applied magnetic field (Qin et al 1995).

The thermal decomposition behaviour of the grown crystals was studied by thermogravimetry (TG) and diffe-

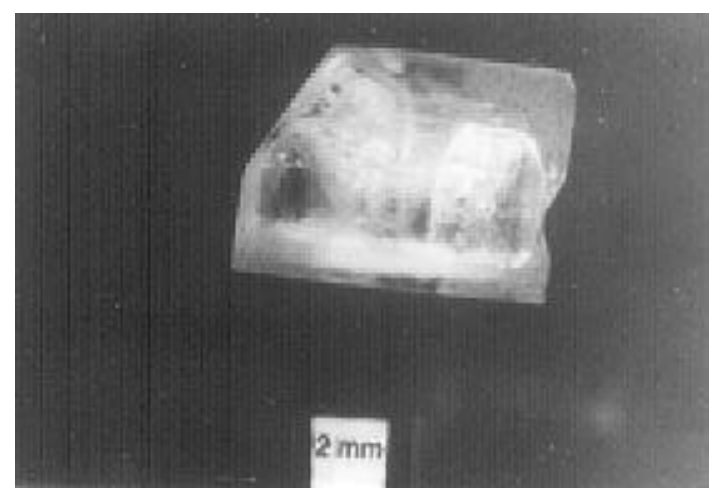

Figure 1. Optical micrograph of strontium tartrate tetrahydrate single crystals grown with $1.5 \mathrm{M}$ solution in gel of density $1.035 \mathrm{~g} / \mathrm{cc}$ at $\mathrm{pH} 6$. rential thermal analysis (DTA). Shimadzu TGA $50 \mathrm{H}$ and DTA-50 H thermal analyser (Japan) was used for obtaining the TG and DTA curves. Experiments were carried out in static nitrogen atmosphere. The initial weight taken for recording the TG curves was $7.85 \mathrm{mg}$ and heating rate was maintained at $10^{\circ} \mathrm{C} \mathrm{min}^{-1}$. The DTA curve was also recorded taking $14.4 \mathrm{mg}$ of $\mathrm{SrT}, 16 \mathrm{mg}$ of SrTMF and $16.4 \mathrm{mg}$ of $\mathrm{SrPbT}$ of the sample. The heating rate was maintained at $15^{\circ} \mathrm{C} \mathrm{min}$. The reference substance for DTA was $\alpha-\mathrm{Al}_{2} \mathrm{O}_{3}$.

\section{Results and discussion}

Perfect crystals of larger dimensions were obtained for $\mathrm{pH}$ values between 6 and 8 and the size of these crystals varied from 4-7 $\mathrm{mm}$ and were transparent with orthorhombic system. In the case of dopant added crystal growth experiment, the nucleation was delayed. As the concentration of the dopants was increased the number of days required for nucleation was also increased. Thus it was found from a series of experiments conducted that addition of $\mathrm{Pb}^{2+}$ increased the nucleation with a reduction in crystal size. With dopant (lead) a large number of crystals obtained were of lower transparency and non faceted. The field promoted growth of the crystals and increased the growth rate. This may be due to the accelerated diffusion (Desai and Shukla 1990) which might have been produced by the magnetic field, as happens when electric field was applied.

TG and DTA curves of $\mathrm{SrC}_{4} \mathrm{H}_{4} \mathrm{O}_{6} \cdot 4 \mathrm{H}_{2} \mathrm{O}$ grown under different experimental conditions are shown in figures 2 and 3. It was observed that the onset of first decomposition begins slightly at different temperatures for each of

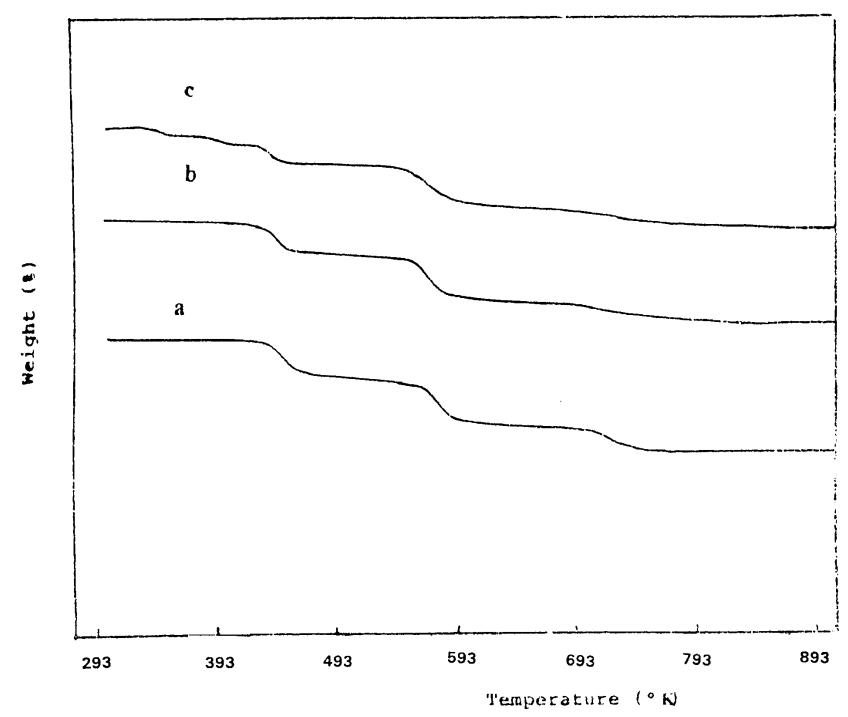

Figure 2. a. TG curve of strontium tartrate tetrahydrate (SrT), b. TG curve of strontium tartrate tetrahydrate crystals grown in presence of magnetic field (SrTMF) and c. TG curve of lead doped strontium tartrate tetrahydrate (SrPbT). 
them indicating different degrees of thermal stability as discussed below.

\subsection{Strontium tartrate $\left(\mathrm{Sr}\left(\mathrm{C}_{4} \mathrm{H}_{4} \mathrm{O}_{6}\right) 4 \mathrm{H}_{2} \mathrm{O}\right)$}

In the thermogravimetric analysis, weight of the sample taken was $7.85 \mathrm{mg}$ and the heating rate was maintained at $10^{\circ} \mathrm{C} \mathrm{min}{ }^{-1}$ in nitrogen atmosphere. Figure 2a shows the TG curve recorded for $\operatorname{Sr}\left(\mathrm{C}_{4} \mathrm{H}_{4} \mathrm{O}_{6}\right) 4 \mathrm{H}_{2} \mathrm{O}$. Here the decomposition process starts at $392 \cdot 5^{\circ} \mathrm{K}$. The first stage of decomposition continues up to $447 \cdot 4^{\circ} \mathrm{K}$, leading to the formation of strontium tartrate monohydrate which is stable up to $506 \cdot 3^{\circ} \mathrm{K}$. The second stage of decomposition starts at $506 \cdot 3^{\circ} \mathrm{K}$ resulting in the formation of strontium oxalate monohydrate $\left(\mathrm{SrC}_{2} \mathrm{O}_{4} \cdot \mathrm{H}_{2} \mathrm{O}\right)$ which remains stable up to $639.4^{\circ} \mathrm{K}$. In the third stage between $639.4^{\circ} \mathrm{K}$ and $766.9^{\circ} \mathrm{K}$ strontium oxalate monohydrate eliminates water molecule and decomposes into strontium carbonate $\left(\mathrm{SrCO}_{3}\right)$. The energy required to dislodge water molecules depends upon how strongly they are locked up in the lattice. As water molecules are ejected from the lattice in two different stages, it appears that the water molecules are locked up in two different ways and thus required different amount of energy for their ejection from the lattice. This is in conformity with the IR spectral studies.

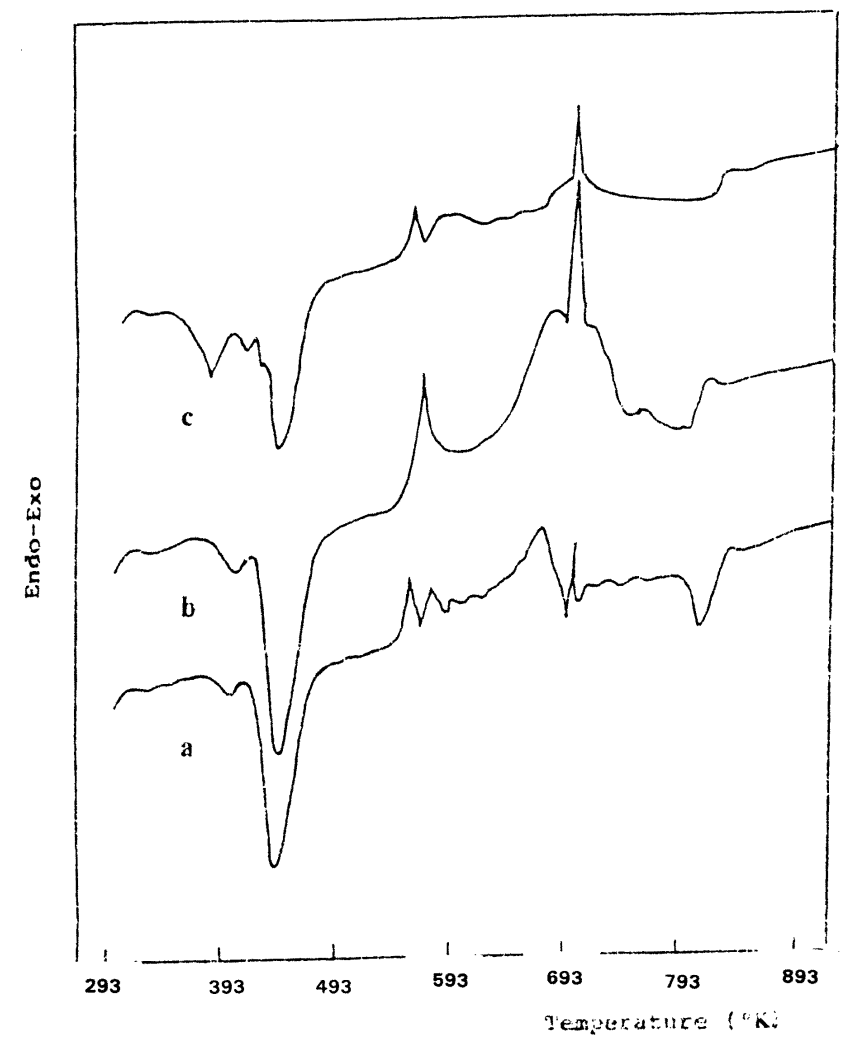

Figure 3. a. DTA curve of strontium tartrate tetrahydrate (SrT), b. DTA curve of strontium tartrate tetrahydrate crystals grown in presence of magnetic field (SrTMF) and c. DTA curve of lead doped strontium tartrate tetrahydrate $(\mathrm{SrPbT})$.
Table 1 summarizes the decomposition steps and the expected and observed mass losses at different steps for $\mathrm{Sr}\left(\mathrm{C}_{4} \mathrm{H}_{4} \mathrm{O}_{6}\right) \cdot 4 \mathrm{H}_{2} \mathrm{O}$. Figure $3 \mathrm{a}$ illustrates DTA curve recorded for strontium tartrate tetrahydrate. The DTA curve was recorded taking $14.4 \mathrm{mg}$ of SrT. The heating rate was maintained at $15^{\circ} \mathrm{C} \mathrm{min}{ }^{-1}$ in nitrogen atmosphere. The DTA shows parallel peaks corresponding to weight losses in TG and the data are presented in table 1. The DTA curve shows an endothermic peak at $397.7^{\circ} \mathrm{K}$ corresponding to the elimination of the three water molecules. Thermal decomposition reactions are usually endothermic. However, some of the DTA peaks are exothermic. This is due to the concomitant oxidation reaction taking place along with decomposition. The results are quite similar to those for other rare earth tartrates reported (Kotru et al 1986a, b). Table 2 gives the summarized results of decomposition process of SrT, SrTMF and SrPbT.

\section{$3.2 \mathrm{Sr}\left(\mathrm{C}_{4} \mathrm{H}_{4} \mathrm{O}_{6}\right) \cdot 4 \mathrm{H}_{2} \mathrm{O}$ grown in the presence of magnetic field $\operatorname{SrT}(M F)$}

Figure $2 \mathrm{~b}$ shows the TG curve recorded for $\mathrm{Sr}\left(\mathrm{C}_{4} \mathrm{H}_{4} \mathrm{O}_{6}\right) \cdot 4 \mathrm{H}_{2} \mathrm{O}$ grown in the presence of magnetic field. Here the decomposition process starts at $389 \cdot 1^{\circ} \mathrm{K}$. The first stage of decomposition continues up to $448 \cdot 2^{\circ} \mathrm{K}$ leading to the formation of strontium tartrate monohydrate which is stable up to $501 \cdot 6^{\circ} \mathrm{K}$. The second stage of decomposition starts at $501 \cdot 6^{\circ} \mathrm{K}$ and is completed at $570 \cdot 7^{\circ} \mathrm{K}$ resulting in the formation of strontium oxalate monohydrate which remains stable up to $661.7^{\circ} \mathrm{K}$. In the third stage between $661.7^{\circ} \mathrm{K}$ and $842.6^{\circ} \mathrm{K}$ strontium oxalate monohydrate decomposes to strontium carbonate. Table 1 provides the summary of the decomposition steps and the expected and observed mass losses. Figure $3 b$ illustrates DTA curve recorded for strontium tartrate tetrahydrate grown in the presence of magnetic field. The DTA curve shows parallel peaks corresponding to the weight losses in TG and the data are presented in table 1 . The DTA curve shows an endothermic peak at $401.5^{\circ} \mathrm{K}$ corresponding to the elimination of three water molecules. Table 2 gives the summary of the results for SrT (MF).

\subsection{Lead doped strontium tartrate $(\mathrm{SrPbT})$}

Figure 2c shows the TG curve recorded for lead doped strontium tartrate tetrahydrate $(\mathrm{SrPbT})$. TG curve reveals that decomposition starts at $360.9^{\circ} \mathrm{K}$. The elimination of water molecules at a lower temperature for lead doped crystal shows that the water molecules are weakly locked up in the doped crystals. The first stage of decomposition continues up to $498.7^{\circ} \mathrm{K}$, leading to the formation of strontium tartrate monohydrate. The second stage of decomposition starts at $498.7^{\circ} \mathrm{K}$ and is completed at $578^{\circ} \mathrm{K}$ resulting in the formation of strontium oxalate monohydrate which remains stable up to $636 \cdot 1^{\circ} \mathrm{K}$. The third 
Table 1. TG results of decomposition process of $\mathrm{SrT}, \mathrm{SrT}(\mathrm{MF})$ and $\mathrm{SrPbT}$.

\begin{tabular}{|c|c|c|c|c|c|}
\hline \multirow[b]{2}{*}{ Stage } & \multirow[b]{2}{*}{ Samples } & \multirow{2}{*}{$\begin{array}{c}\text { Temperature range } \\
\left({ }^{\circ} \mathrm{K}\right)\end{array}$} & \multicolumn{2}{|c|}{ Mass loss $(\%)$} & \multirow[b]{2}{*}{ Reactions } \\
\hline & & & Observed & Calculated & \\
\hline \multirow[t]{3}{*}{ I } & $\mathrm{SrT}$ & $392 \cdot 5-506 \cdot 3$ & $16 \cdot 85$ & \multirow[t]{3}{*}{$17 \cdot 55$} & \multirow[t]{3}{*}{$\mathrm{SrC}_{4} \mathrm{H}_{4} \mathrm{O}_{6} \cdot 4 \mathrm{H}_{2} \mathrm{O}-\mathrm{SrC}_{4} \mathrm{H}_{4} \mathrm{O}_{6} \cdot \mathrm{H}_{2} \mathrm{O}$} \\
\hline & SrTMF & $381 \cdot 1-501 \cdot 6$ & $16 \cdot 82$ & & \\
\hline & $\mathrm{SrPbT}$ & $360 \cdot 9-498 \cdot 7$ & $18 \cdot 19$ & & \\
\hline \multirow[t]{3}{*}{ II } & $\mathrm{SrT}$ & $506 \cdot 3-639 \cdot 4$ & $20 \cdot 04$ & \multirow[t]{3}{*}{$23 \cdot 65$} & \multirow[t]{3}{*}{$\mathrm{SrC}_{4} \mathrm{H}_{4} \mathrm{O}_{6} \mathrm{H}_{2} \mathrm{O}-\mathrm{SrC}_{2} \mathrm{O}_{4} \mathrm{H}_{2} \mathrm{O}$} \\
\hline & SrTMF & $501 \cdot 6-661 \cdot 7$ & $20 \cdot 63$ & & \\
\hline & $\mathrm{SrPbT}$ & $498 \cdot 7-636 \cdot 1$ & $19 \cdot 68$ & & \\
\hline \multirow[t]{3}{*}{ III } & SrT & $639 \cdot 4-766 \cdot 9$ & $10 \cdot 75$ & \multirow[t]{3}{*}{$9 \cdot 32$} & \multirow[t]{3}{*}{$\mathrm{SrC}_{2} \mathrm{O}_{4} \mathrm{H}_{2} \mathrm{O}-\mathrm{SrCO}_{3}$} \\
\hline & SrTMF & $661 \cdot 7-842 \cdot 6$ & $10 \cdot 02$ & & \\
\hline & $\mathrm{SrPbT}$ & $636 \cdot 1-857 \cdot 2$ & $11 \cdot 09$ & & \\
\hline
\end{tabular}

$\mathrm{SrT}, \mathrm{SrC}_{4} \mathrm{H}_{4} \mathrm{O}_{6} \cdot 4 \mathrm{H}_{4} \mathrm{O}$ pure crystal; $\mathrm{SrTMF}, \mathrm{SrC}_{4} \mathrm{H}_{4} \mathrm{O}_{6} \cdot 4 \mathrm{H}_{2} \mathrm{O}$ grown in presence of magnetic field; and $\mathrm{SrPbT}, \mathrm{SrC}_{4} \mathrm{H}_{4} \mathrm{O}_{6} \cdot 4 \mathrm{H}_{2} \mathrm{O}$ grown with dopant (lead).

Table 2. DTA data of SrT, SrT (MF) and SrPbT.

\begin{tabular}{|c|c|c|}
\hline $\begin{array}{l}\text { SrT } \\
\text { Temperature range } \\
\left({ }^{\circ} \mathrm{K}\right)\end{array}$ & $\begin{array}{c}\text { SrT }(\mathrm{MF}) \\
\text { Temperature range } \\
\left({ }^{\circ} \mathrm{K}\right)\end{array}$ & $\begin{array}{c}\mathrm{SrPbT} \\
\text { Temperature range } \\
\left({ }^{\circ} \mathrm{K}\right)\end{array}$ \\
\hline $\begin{array}{l}397.7 \text { endo } \\
441.5 \text { endo } \\
586.6 \text { exo } \\
567.0 \text { endo } \\
669.8 \text { exo } \\
692.3 \text { endo } \\
700 \cdot 1 \text { exo } \\
805.7 \text { endo }\end{array}$ & $\begin{array}{l}401 \cdot 5 \text { endo } \\
441 \cdot 2 \text { endo } \\
563 \cdot 9 \text { exo } \\
687 \cdot 3 \text { endo } \\
700 \cdot 8 \text { exo } \\
789 \cdot 2 \text { endo } \\
810 \cdot 6 \text { exo }\end{array}$ & $\begin{array}{l}380 \text { endo } \\
411 \cdot 8 \text { endo } \\
439 \cdot 3 \text { endo } \\
559 \cdot 2 \text { exo } \\
567 \cdot 4 \text { endo } \\
704 \cdot 1 \text { exo }\end{array}$ \\
\hline
\end{tabular}

endo, endothermic reaction; exo, exothermic reaction; SrT, $\mathrm{SrC}_{4} \mathrm{H}_{4} \mathrm{O}_{6} \cdot 4 \mathrm{H}_{4} \mathrm{O}$ pure crystal; $\mathrm{SrTMF}, \mathrm{SrC}_{4} \mathrm{H}_{4} \mathrm{O}_{6} \cdot 4 \mathrm{H}_{2} \mathrm{O}$ grown in presence of magnetic field; and $\mathrm{SrPbT}, \mathrm{SrC}_{4} \mathrm{H}_{4} \mathrm{O}_{6} \cdot 4 \mathrm{H}_{2} \mathrm{O}$ grown with dopant (lead).

stage starts at $636 \cdot 1^{\circ} \mathrm{K}$ and is completed at $857 \cdot 2^{\circ} \mathrm{K}$ corresponding to the conversion of strontium oxalate monohydrate into strontium carbonate. The thermo analytical data are given in table 2 for lead doped strontium tartrate $(\mathrm{SrPbT})$. The DTA curve obtained is shown in figure 3c. DTA shows parallel peaks corresponding to the weight losses in TG and the data are presented in table 1. The DTA curve shows an endothermic peak at $380^{\circ} \mathrm{K}$ corresponding to the elimination of three water molecules.

\section{Conclusions}

Thermal study confirms that the crystals grown contains four water molecules in the unit cell. TG results were quite similar for SrT, SrTMF and SrPbT, as expected. This study also reveals that material is unstable even at lower energies. The DTA curves show parallel peaks corresponding to weight losses in TG curves. The initial stage of decomposition corresponding to the elimination of three water molecules takes place at 392.5, 389.1, $360 \cdot 9^{\circ} \mathrm{K}$ for the SrT, SrTMF and SrPbT. As water molecules are ejected from the lattice in two different stages, it appears that the water molecules are locked up in the lattice in two different ways. The thermal decomposition reactions are usually endothermic. However, some of the DTA peaks are exothermic. This is due to the concomitant oxidation reactions taking place along with decomposition reactions. The final solid products of thermal decompositions of those investigated are carbonates. Thermal study reveals that water molecules are locked up in the lattice with different strengths in the grown crystals. The bonding is strongest in SrT crystals. The locking of water molecules is weaker in SrPbT than SrT (MF).

\section{References}

Bohandy J and Murphy J C 1968 Acta Crystallogr. B24 286

Desai C C and Shukla M J 1990 Cryst. Res. Tech. 25871

Higavshitani K, Kage A, Katamura S, Imai K and Hatade S J 1993 Colloid Interface Sci. 15690

Henisch H K 1973 Crystal growth in gels (University Park, PA: The Pennsylvania University Press)

Henisch H K, Dennis J and Hanoka J I 1965 J. Electro Chem. Soc. 112 627; Phys. Chem. Solids 26493

Jain Anima, Bhat Sushama, Pandita Sanjay, Kaul M L and Kotru P N 1997 Bull. Mater. Sci. 201089

Kotru P N, Gupta N K, Raina K K and Koul M L 1986a Bull. Mater. Sci. 8547

Kotru P N, Gupta N K, Raina K K and Sarma I B 1986b J. Mater. Sci. 2183

Qin Z, Dost S, Djilali N and Tabarrok B 1995 J. Cryst. Growth 153131 